\title{
RESSOCIALIZAÇÃO DO PRESO: UMA REVISÃO BIBLIOGRÁFICA
}

\author{
Cássio Samuel Dick ${ }^{1}$
}

RESUMO: Na Lei de Execução Penal estão estabelecidas as normas fundamentais que regerão os direitos e obrigações do sentenciado no curso da execução da pena. Constitui-se na Carta Magna dos presos, tendo como finalidade atuar como um instrumento de preparação para o retorno ao convívio social do preso. O trabalho é algo que traz inúmeros benefícios para a vida do ser humano, é por meio dele que as pessoas se integram na sociedade, se desenvolvem e nele encontram seu sustento. Assim como a prisão, desde os primórdios, o trabalho vem passando por constantes evoluções, colaborando com o ser humano para que este possa se relacionar, sendo por meio dele que as pessoas se transformam e desenvolvem-se como profissionais, adquirindo novos conhecimentos e propondo uma nova realidade. Segundo a própria instituição, o trabalho constitui o principal instrumento para atingir a ressocialização dos presos. Essa pesquisa é uma revisão bibliográfica que busca mostrar a ressocialização da população carcerária na sociedade. Tem por objetivo verificar a perspectiva dos apenados em relação ao seu retorno a sociedade, reinserção no mercado de trabalho; bem como investigar a relação de afeto existente entre os presos e suas famílias. Pretende conhecer a realidade em que os mesmos se encontram e, verificar se há movimentos internos nos Presídios que colaborem para a reinserção social. Assim, concluiu-se que várias são as alternativas para o sistema penitenciário já previstas na legislação vigente. Em nosso estudo foi abordada a ressocialização por meio do trabalho, e foi apontada a finalidade da pena não somente para punir, mas para ressocializar.

Palavras-chave: Ressocialização do Preso. Sistema Penitenciário. Sociedade.

\section{INTRODUÇÃO}

O Brasil tem a terceira maior população carcerária do mundo, segundo o Levantamento Nacional de Informações Penitenciárias - Infopen - realizado pelo Departamento Penitenciário Nacional.

\footnotetext{
${ }^{\text {I }}$ Bacharel em Direito pela Universidade de Santa Cruz do Sul- UNISC. Pós- graduado em : Gestão de Sistemas Prisionais pela FAVENI. E-mail: cassiosamuel@bol.com.br.
} 
$\mathrm{Na}$ Lei de Execução Penal estão estabelecidas as normas fundamentais que regerão os direitos e obrigações do sentenciado no curso da execução da pena. Constitui-se na Carta Magna dos presos, tendo como finalidade atuar como um instrumento de preparação para o retorno ao convívio social do preso.

A Superintendência dos Serviços Penitenciários - SUSEPE, foi criada no Estado do Rio Grande do Sul, para a necessidade de recuperar o indivíduo apenado, oferecendo-lhe meios de reinserção social. Segundo a própria instituição, o trabalho constitui o principal instrumento para atingir a ressocialização dos presos.

O conhecimento por parte da instituição penitenciária da necessidade de uma organização do trabalho prisional que perpasse pela relação entre prazer e sofrimento no trabalho possibilita a mudança e gera repercussões positivas no processo de ressocialização e, consequentemente, na vida egressa dos apenados, bem como na vida daqueles com quem esses se relacionam.

O entendimento sobre a ressocialização do preso é de suma importância, para que seja realizada uma nova reintegração dessa pessoa na sociedade, fazendo com que cumpra as regras e se relacione novamente com todos, de forma igual e digna, como garante o Art. $5^{\circ}$ da Constituição Federal. (CAMPOS, A. C. A; SANTOS, E. L. 2014).

Considera-se ressocialização o bom aproveitamento dos programas aplicados ao preso por meio da custódia, da prestação de assistência jurídica, psicossocial, à saúde, educacional, trabalhista, religiosa, bem como a garantia da visitação e do lazer.

(FREITAS, G.C. 2013).

Haja vista que este trabalho mostrar a importância da ressocialização dos apenados, para retornar ao convívio da sociedade.

O presente estudo tem como objetivo mostrar o trabalho prisional na prática de ressocialização de detentos a sociedade.

\section{2- REFERENCIAL TEÓRICO}

\section{1- A RESSOCIALIZAÇÃO}

Há uma inegável discrepância entre nossa realidade prisional e o que é preconizado em nossa legislação. A falta de políticas públicas e o descaso com as normas existentes fazem com que a ressocialização não aconteça. Para possibilitar a ressocialização dos condenados é necessário 
colocar em prática as normas existentes em nosso ordenamento jurídico, especialmente na Lei de Execução Penal, tendo como base as medidas de assistência aos apenados.

A solução para que a ressocialização se efetive é uma política carcerária que garanta dignidade ao preso em todos os sentidos, desde a prática de atividade física até o acesso ao trabalho profissionalizante. É através da educação e da profissionalização do condenado que se tornará possível oferecer condições para o reingresso no mundo do trabalho e consequentemente no convívio social.

As iniciativas governamentais buscam alcançar maior aproximação e adequação da ressocialização aos fins práticos, em virtude de o Estado ter obrigação de oferecer o tratamento penal ao apenado. Nas pautas governamentais existe lugar para questionamentos, como: qual a melhor forma de punir? De que forma punir e recuperar ao mesmo tempo? Que estratégias podem ser adotadas visando à reintegração social? Como construir programas que tenham efeito na trajetória futura do indivíduo encarcerado? (ANDRADE, C. C. et al, 2015).

Ao contrário da proposta de ressocialização apontada no Direito Penal, Lei de Execução PenalLEP e Regulamento Disciplinar Prisional-REDIPRI, ao impor sofrimento, dor e humilhação ao preso, a prisão torna o preso uma pessoa sem perspectivas futuras, o faz pensar em vingança, o faz inconformado com a situação na qual é lançado: desemprego, discriminação, revolta e miséria, e, como eles mesmos dizem, a prisão os faz pessoas piores. É exatamente por não cumprir este objetivo, de tornar o preso "dócil",

fazê-lo um cidadão de bem, conformado com sua situação, é que muitos voltam a recorrer ao crime na busca de terem suas necessidades materiais e sociais satisfeitas.

(OLIVEIRA, N. M, et al, 20I7).

Ainda que historicamente as prisões tenham surgido com a finalidade de punição para recuperação moral dos detentos, ratifica que este modelo não preenche as necessidades políticosociais de recuperação da população carcerária para o retorno à sociedade. Afastar o sujeito de seu ambiente sem oferecer condições de saúde, trabalho ou de construção de um novo projeto de vida tem resultado no aumento evidente da violência institucional e social, afetando diretamente os índices de reincidência na criminalidade e o consequente aumento da população carcerária. A ressocialização só será possível quando o indivíduo a ser ressocializado e o encarregado da 
ressocialização aceitem ou compartilhem o mesmo entendimento acerca da norma social vigente. (BARCINSKI, M, et al, 2017).

Entre 2007 e 2013, o governo federal lançou programas de política penitenciária que contemplam, entre outras áreas, o trabalho prisional. Em 2007, o Programa Nacional de Segurança Pública com Cidadania (Pronasci), composto de 94 ações articuladas em 14 ministérios e estruturadas em grandes eixos de Segurança Pública, previa também a modernização das instituições de Segurança Pública e do Sistema Prisional. Essa modernização focava na abertura de $4 \mathrm{I}$ mil novas vagas até $201 \mathrm{I}$, em especial presídios para a faixa etária entre 18 e 24 anos, com condições mínimas para cumprir o ideal da "reintegração social”, com salas de aula, laboratórios de informática e biblioteca nas unidades prisionais. (MACHADO, B. A; SLONIAK, M. A, 2015).

Para que a ressocialização seja realizada com efetividade, ela deverá ser formada por três pilares fundamentais que são: a educação, a capacitação profissional e o trabalho. Esses pilares possuem como meta a ampliação do grau de escolaridade do apenado, qualificando-o profissionalmente e depois, ainda dentro do estabelecimento prisional, inseri-lo no mercado de trabalho. A educação, por ser um direito de todos e obrigação do Estado, conforme descrito na CRFB/1988, é um direito fundamental para a concretização da liberdade e que será utilizada para o bem comum. Deste modo, os estabelecimentos prisionais buscam elevar a escolaridade dos apenados, pois uma parcela significativa possui baixa escolaridade ou nenhuma (ensino fundamental) e outros não possuem o ensino médio completo. $O$ apenado que frequenta as aulas, será contada da seguinte forma: a cada i6 horas de aulas ministradas, diminui-se um dia de sua pena. E para que isto ocorra, o governo contrata professores para darem aulas aos apenados e há também, casos de apenados que tiveram a oportunidade de sair para realizar a prova do Enem, lembrando que esta saída irá depender de sua conduta dentro do presídio. (CALMON, J. V, 20I4).

Tendo em vista o apenado trabalhar, é dever e direito do mesmo, estabelecidos na Lei de Execução Penal, o trabalho é considerado, por muitos, uma verdadeira terapia - a laborterapia. Terapia porque incute no preso a vontade de sentir-se útil e produtivo, aumenta sua autoestima, propicia a inclusão e integração com a sociedade, mostrando novos caminhos fora da criminalidade. Além disso, gera renda para o preso e sua família, fortalecendo o núcleo familiar e, por consequência, promovendo o crescimento da economia local. As formas de trabalho são:

- Trabalho interno, que acontece dentro da unidade prisional; 
- Trabalho externo, que ocorre extramuros, com presos do regime semiaberto, aberto e fechado. (JUNIOR, J. C. M. N, 20II).

Denota-se que a ressocialização do apenado só se torna efetiva quando de fato ocorre a integração entre sociedade e condenado, na medida em que, somente pela convivência o indivíduo sentir-se-á incluso, se afastando da marginalidade por enxergá-la como prejudicial aquele grupo do qual entende fazer parte. Dessa forma, deve ser derrubada a barreira do preconceito, com o objetivo de permitir ao preso conviver harmoniosamente com o seu próximo, após o cumprimento da pena. (RIBEIRO, J. R. F, et al, 2018).

O trabalho é algo que traz inúmeros benefícios para a vida do ser humano, é por meio dele que as pessoas se integram na sociedade, se desenvolvem e nele encontram seu sustento. Assim como a prisão, desde os primórdios, o trabalho vem passando por constantes evoluções, colaborando com o ser humano para que este possa se relacionar, sendo por meio dele que as pessoas se transformam e desenvolvem-se como profissionais, adquirindo novos conhecimentos e propondo uma nova realidade.

(CORREAA, M. F. C; NOGUEIRA, J. P. F, 2015).

\section{2- A RESSOCIALIZAÇÃO ATRAVÉS DO TRABALHO}

Ressocialização é um projeto desenvolvido pela política penitenciária, com o objetivo de resgatar os apenados, e, assim, quando deixarem a penitenciária, venham a ser inseridos no meio social. No ordenamento jurídico brasileiro, as penitenciárias apresentam-se em estado preocupante, pois, na maioria das vezes, não oferecem as condições mínimas que são necessárias para recuperação dos indivíduos. Dessa forma, analisaremos as condições necessárias para a reinserção do apenado na sociedade. Quando se trata de ressocialização, não existem fórmulas, mas, sim, alternativas de ação, visto que esse problema não poderá ser resolvido com preceitos simplistas. Com isso, não devemos atribuir aos dispositivos penais o ônus de concretizar, na totalidade, a ressocialização do apenado, desconsiderando a existência de outros programas e métodos de controle que o meio social e o Estado devem organizar com esse objetivo, que pode ser por intermédio da educação, do incentivo familiar ou religioso. (NERY JÚNIOR, 2006). 
É necessário que a pena de prisão tenha nova finalidade, não interessando apenas castigar o apenado, mas, sim, dar ao indivíduo novas condições para a reinserção na sociedade, de forma efetiva. Nesse sentido, o trabalho prisional contribui com o aumento da população economicamente ativa, beneficiando os setores nos quais os apenados laboram, pela disponibilidade de obreiros dotados de experiência na área em que desenvolvem suas atividades. (MIRABETE, 2004).

O trabalho carcerário constitui uma das principais formas de combater o maior obstáculo do sistema penitenciário brasileiro, que é a superlotação. A redução da população prisional seria uma das consequências do fato de a Lei de Execução Penal beneficiar o apenado que trabalha, com a diminuição progressiva de sua pena. (RODRIGUES, V. F. S. R; CAVALCANTI, S. C. M, 2017).

\section{2- NOVAS PROPOSTAS PARA EFICÁCIA DA LEP}

Redução do número de detentos por cela, plano de educação para presos e incentivo a penas alternativas são algumas das medidas previstas no anteprojeto elaborado pela comissão de juristas criada para estudar e propor mudanças na Lei de Execução Penal. Instalada no dia 4 de abril de 2013, o objetivo é atualizar a Lei 7.210 de 1984, mais conhecida pelo nome de Lei de Execução Penal (LEP).

Há 28 anos em vigor, a LEP, que trata das regras para o cumprimento de sentenças e dos direitos e deveres do condenado, pode ajudar a mudar a realidade atual do sistema prisional. Entre os assuntos discutidos pelos juristas estão a superlotação do sistema prisional brasileiro e problemas como racionamento de água, comida estragada, falta de medicamentos e humilhação na hora da visita. São reclamações comuns feitas por detentos e seus parentes em quase todos os presídios brasileiros.

Nos sete meses de funcionamento da comissão também foram debatidas a possibilidade de extinção do alvará de soltura; a duração da prisão preventiva; a criação de um rol de medidas alternativas; e novas regras para as saídas temporárias dos presos.

Entre as novidades, o texto do anteprojeto traz um limite de lotação para cada penitenciária, facilita a obtenção de regime aberto aos presos mais antigos e fixa novas regras para as saídas temporárias. O trabalho foi pensado para incentivar a reinserção social dos condenados. Para isso, 
a comissão propõe, entre outras mudanças, a substituição das casas de albergado pela prisão domiciliar combinada com prestação de serviços comunitários.

Para evitar a permanência na cadeia depois do cumprimento da pena, o relatório cria um sistema de advertência, que obriga o diretor do presídio a informar o juiz sobre o benefício com 30 dias de antecedência. Um dos maiores avanços está na inclusão das secretarias estaduais no conselho que define as políticas do setor. (BRASIL. Lei de Execução Penal, 1984).

\section{3- METODOLOGIA}

Essa pesquisa é uma revisão bibliográfica que busca mostrar a possibilidade de ressocialização do preso na sociedade.

Para confecção do presente trabalho, utilizaremos revistas científicas e materiais extraídos da Internet, salientando-se o que tem de mais atual sobre a ressocialização do preso e suas legislações.

\section{4- DISCUSSÃO E RESULTADOS}

Este estudo tem o objetivo de esclarecer e ressaltar o benefício do trabalho dentro do contexto presídio, para que, posteriormente a sua saída, o processo de inserção profissional de um exdetento seja eficaz.

Ter uma ocupação, para quem se encontra recluso, é essencial para que a mente não fique maquinando coisas ruins, que vão contra os princípios da sociedade. Assim, tirar o preso da ociosidade é de fato imprescindível.

Adotar medidas para ensinar profissões, para fazer com que o detento crie um sentimento pelo trabalho é relevante para a sua preparação, para que o ex-presidiário não volte a reincidir, não justificando que este declare que voltou ao crime porque não tinha o conhecimento de uma profissão, que não sabia executá-la. Assim como o autor Varella (1999) ressalta que ensinar uma profissão ao ex-detento dentro da prisão, traz para ele uma nova perspectiva de futuro, ao contrário de largálo para que se socialize na sociedade sozinho.

Outro autor Alex et al. (2002), fala também que a oportunidade de trabalhar aumenta a probabilidade de o detento se regenerar, pois muitos, ao cumprirem a pena e saírem da prisão, não conseguem emprego e são excluídos da sociedade. O trabalho oferece uma condição para que se 
possa alterar a situação em que os presos se encontram, produzindo algo, propondo uma mudança de vida.

Por outro lado, um trabalho que não ofereça grande coisa que fazer, como é o caso específico do trabalho prisional, pois as necessidades de envolvimento dos apenados com o conteúdo da tarefa nada representam, é fonte geradora de enorme aumento da carga psíquica e, consequentemente, de maior desajuste do apenado. E é justamente aí que deveria residir a maior preocupação da organização penitenciária, uma vez que seu principal objetivo é de reeducar os apenados por meio do trabalho.

Como visto, os autores descrevem a importância do trabalho tanto dentro quanto fora do presídio. a consciência do quanto é necessário trabalhar para sobreviver, através do seu esforço e adquirir ainda, amor pelo trabalho.

Findando assim nossa discussão a partir do qual conhecemos que o trabalho ocupa na vida do detento, enquanto recluso no presídio e a influência do trabalho na ressocialização do exdetento após a saída da prisão.

\section{CONSIDERAÇÕES FINAIS}

São miseráveis as condições em que estão os presos, tendo seus direitos anulados pela falta de estrutura do sistema carcerário. A realidade do sistema prisional brasileiro, confirma o que diz a teoria agnóstica da pena, que se mostra incapaz de exercer a função de ressocialização do infrator para o meio social.

O que se busca é a humanização na aplicação das penas, transformação no e do sistema prisional para que este atinja sua finalidade de ressocialização do preso, pois o acréscimo de sofrimento não previsto em lei não se justifica no cumprimento da pena e nem acrescenta nada ao preso.

Todo o ser humano e, principalmente, os apenados, deve encontrar no trabalho condições que permitam a busca de seu questionamento interior e traçar a sua história, para que encontrem o equilíbrio necessário ao seu real ajustamento social.

O trabalho prisional deveria funcionar como atenuante nesse processo de mortificação. A instituição penitenciária, embora apresente as características de instituição total, deveria preocupar-se mais com a possibilidade de fazer com que o indivíduo apenado encontre uma nova 
identidade, cujo reflexo provenha de um meio social ajustado, onde o trabalho passe a ser concebido como fator gerador de inúmeras possibilidades de desenvolvimento pessoal e, consequentemente, de uma identidade social.

Dessa forma, pode-se sugerir, por meio do conhecimento dessa realidade que, para proceder a uma reforma na atual organização do trabalho prisional, em que se possam atingir índices mais elevados de ressocialização, deveriam existir estudos referentes às reais condições do corpo funcional do sistema penitenciário, analisando a forma como percebem o trabalho prisional. Deveria ser feita também uma reavaliação da Lei de Execuções Penais. E, ainda, estudos no sentido de conscientizar a sociedade do seu papel nesse processo de ressocialização: não adianta reorganizar o trabalho prisional e, por ele, capacitar o indivíduo ao convívio social, se a própria sociedade continua a negá-los.

A sociedade em contato com o recluso durante o cumprimento de sua pena, certamente mudará seu olhar sobre o mesmo, deixando ele de ser "invisível" a ela e facilitando, assim, sua reinserção na sociedade. Sociedade, esta, que o acompanhou durante seu aprisionamento e colaborou em sua ressocialização, o que é fundamental para a reintegração do preso à comunidade.

Assim, concluo que várias são as alternativas para o sistema penitenciário já previstas na legislação vigente. Em nosso estudo foi abordada a ressocialização por meio do trabalho, e foi apontada a finalidade da pena não somente para punir, mas para ressocializar. 


\section{REFERÊNCIAS}

ALEX, A. A. et al. Os direitos humanos do preso e a ética. Jurisvox: Patos de Minas. n.4, p.III-I22, dez. 2002.

ANDRADE, C. C; JÚNIOR, A. O; BRAGA, A. A; JAKOB, A. C; ARAÚJO, T. D. O Desafio da Reintegração Social do Preso: Uma Pesquisa em Estabelecimentos prisionais. Ipea. Brasília, 2015 .

BARCINSKI, M; CÚNICO. S. D; BRASIL, M. V. Significados da ressocialização para agentes penitenciárias em uma prisão feminina: entre o cuidado e o controle. Temas psicol. vol.25 no.3 Ribeirão Preto, 2017.

BRASIL. Constituição (1988). Constituição da República Federativa do Brasil. Brasília, DF, Senado, 1998.

BRASIL. Lei de Execução Penal (1984). Institui a Lei de Execução Penal. Diário Oficial da União de 13 de julho de 1984. Brasília, in de julho de 1984

CALMON, J. V. Analise do Processo de Ressocialização com Foco à Reinserção do Indivíduo na Sociedade. Disponível em: 〈https://monografias.brasilescola.uol.com.br/direito/anAliseprocesso-ressocializacaocom-

foco-a-reinsercao-individuo.htm>.

CAMPOS, A. C. A; SANTOS, E. L. A RESSOCIALIZAÇÃO DO PRESO JUNTO À SOCIEDADE. Rev. Cien. Elet. do Curso de Direito. 6ª Edição, 2014.

CORRÊA, M. F. C; NOGUEIRA, J. P. F. O PAPEL DO TRABALHO NA CONSTRUÇÃO DA CONSCIÊNCIA DOS RECUPERANDOS DURANTE A RECLUSÃO. Pouso Alegre, ano II, no 2, 2015 . 
FREITAS, G.C. PROJETO DE PESQUISA APLICADA: “A RESSOCIALIZAÇÃO DO PRESO FRENTE AO SISTEMA PENITENCIÁRIO BRASILEIRO”. Disponível em: <http:// www.escolasuperior.mppr.mp.br/arquivos/File/Projetos\%2ode\%2oPesquisa\%2oAplicada/ Gisele_Caldeira_de_Freitas.pdf $>$.

JUNIOR, J. C. M. N. Mão de Obra Carcerária. Ministério Público do Estado de Goiás, 201 .

LEMOS, A. M; MAZZILLI, C; KLERINGK1, L.R. Análise do trabalho prisional: um estudo exploratório. Rev. adm. contemp. vol.2 no.3 Curitiba, 1998.

MACHADO, B. A; SLONIAK, M. A. DISCIPLINA OU RESSOCIALIZAÇÃO? RACIONALIDADES PUNITIVAS, TRABALHO PRISIONAL E POLÍTICA PENITENCIÁRIA. Rev. direito GV, vol.II, no.I, São Paulo, 2015.

OliveirA, N. M; HENRIQUE. K. S; SIQUEIRA. P. P, CleR. T; CARVALHO, M. H. SISTEMA PENAL BRASILEIRO: RESSOCIALIZAÇÃO OU REAJUSTAMENTO? II Jornada de Iniciação Científica da FACIG, 2017.

RIBEIRO, J. R. F; BRITO, R. G. G; OLIVEIRA, T. B. A RESSOCIALIZAÇÃO DO APENADO POR MEIO DA PARTICIPAÇÃO DA SOCIEDADE: O TRABALHO COMO INSTRUMENTO NO PROCESSO DE REINTEGRAÇÃO. Ver. do Dir, vol. 5, no. I, 2018.

RODRIGUES, V. F. S. R; CAVALCANTI, S. C. M. O SISTEMA PRISIONAL E A RESSOCIALIZAÇÃO DO PRESO ATRAVÉS DO TRABALHO. Revista FACISA ONLINE, vol. 6, n.2, Barra do Garças - MT, 2017.

VARELLA, D. Estação Carandiru. São Paulo: Companhia das Letras, I999. 